\title{
Rituals decrease the neural response to performance failure
}

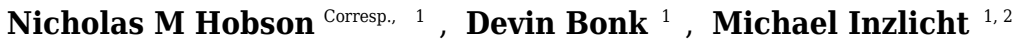 \\ 1 Department of Psychology, University of Toronto, Toronto, Ontario, Canada \\ 2 Management, Rotman School of Management, Toronto, Ontario, Canada \\ Corresponding Author: Nicholas M Hobson \\ Email address: nick.hobson@utoronto.ca
}

Rituals are found in all types of performance domains, from high-stakes athletics and military to the daily morning preparations of the working family. And yet despite their ubiquity and widespread importance for humans, we know very little of ritual's causal basis and how (if at all) they facilitate goal-directed performance. Here, in a fully preregistered pre/post experimental design, we examine a candidate proximal mechanism, the error-related negativity (ERN), in testing the prediction that ritual modulates neural performance-monitoring. Participants completed an arbitrary ritual - novel actions repeated at home over one week - followed by an executive function task in the lab during electroencephalographic (EEG) recording. Results revealed that relative to pre rounds, participants showed a reduced ERN in the post rounds, after completing the ritual in the lab. Despite a muted ERN, there was no evidence that the reduction in neural monitoring led to performance deficit (nor a performance improvement). Generally, the findings are consistent with the longstanding view that ritual buffers against uncertainty and anxiety. Our results indicate that ritual guides goal-directed performance by regulating the brain's response to personal failure. 
1

2

3

4

5

6

7

8

9

10

11

12

13

14

15

16

17

18

19

20

21

22

23

24

25

26
Rituals decrease the neural response to performance failure

\author{
Nicholas M. Hobson ${ }^{1} \quad$ Devin Bonk $^{1} \quad$ Michael Inzlicht ${ }^{1,2}$
}

1. University of Toronto Department of Psychology

2. Rotman School of Management, University of Toronto

WORD COUNT: 9095

Please address all correspondence to:

Nicholas M. Hobson

University of Toronto, Department of Psychology

1265 Military Trail

Toronto, Ontario M1C 1A4, Canada

e-mail: nick.hobson@utoronto.ca

telephone: 416-208-4868 


\section{Abstract}

29 Rituals are found in all types of performance domains, from high-stakes athletics and military to

30

31

32

33

34

35

36

37

the daily morning preparations of the working family. And yet despite their ubiquity and widespread importance for humans, we know very little of ritual's causal basis and how (if at all) they facilitate goal-directed performance. Here, in a fully pre-registered pre/post experimental design, we examine a candidate proximal mechanism, the error-related negativity (ERN), in testing the prediction that ritual modulates neural performance-monitoring. Participants completed an arbitrary ritual - novel actions repeated at home over one week - followed by an executive function task in the lab during electroencephalographic (EEG) recording. Results revealed that relative to pre rounds, participants showed a reduced ERN in the post rounds, after completing the ritual in the lab. Despite a muted ERN, there was no evidence that the reduction in neural monitoring led to performance deficit (nor a performance improvement). Generally, the findings are consistent with the longstanding view that ritual buffers against uncertainty and anxiety. Our results indicate that ritual guides goal-directed performance by regulating the brain's response to personal failure.

3


55

56

57

58

59

60

61

62

63

64

65

66

67

\section{Rituals decrease the neural response to performance failure}

Rituals are human universals. As broad behaviors existing across multiple domains, rituals can be thought of as formal sequences characterized by rigidity and repetition that are embedded in a larger system of meaning. In ritual, ordinary sequenced actions become transformed, like when an athlete dons equipment from bottom-to-top (but not top-to-bottom) as a pregame ritual. A puzzling feature of many rituals is that they require a person to invest time and energy into completing the actions, often with immediate instrumental value. In a way then, rituals pose an economic cost problem (Irons, 1996): Why do people engage in these behaviors - often repeatedly, and over a lifetime - if they reveal no direct benefit to the self?

Performance rituals may offer insight into this question. Research and anecdotal evidence suggests that these types of rituals influence goal-regulated behaviors by heightening motivation and minimizing extraneous sources of anxiety. Research to date has mostly investigated preestablished rituals, in which the actions are tied to broader personal meaning, precluding us from knowing the precise causal impact of the ritual itself. Thus, to examine ritual's underlying causal properties, we use novel, lab-created ritual actions and control for the pre-established features tied to the broader ritual context. In a fully pre-registered experiment (https://osf.io/hcmkp/) we directly examine the impact of arbitrary rituals on the task performance and on the associated brain-based regulatory system.

\section{Ritual and goal-directed performance}

Rituals often precede important tasks and performance events, such as games, sports competitions, military operations, presentations, and tests. Ethnographic research has documented the importance of these rituals: Anthropological evidence from ancestral cultures finds that taboo rituals - those which prescribe rules of conduct and order - tend to increase 
80

81

82

83

84

during times of dangerous hunting/fishing performances (Malinowski, 1954; Sosis, 2000);

professional and amateur athletes feel compelled to do the exact same warm-up ritual before every game (e.g., Rotella \& Cullen, 1995); military culture espouses disciplined excellence through ritualistic training programs (e.g., King, 2006; McNeill, 1997); and even popular blog posts, with titles like "The Value of Ritual in Your Workday" (Bregmen, 2010), give readers advice on how to utilize rituals for achieving small, day-to-day goals (e.g., Reynolds, 2011). Despite the ubiquity of performance rituals, very little is actually known about how these behaviors influence goal-directed performance, if at all.

In performance domains, most notably in sports athletics, there is some evidence showing rituals serve a regulatory function. For instance, performing rituals during athletic events, like right before shooting a free-throw in basketball, helps players perform better (Czech, Ploszay, \& Burke, 2004; Lobmeyer \& Wasserman, 1986; Predebon \& Docker, 1992), especially in highstakes competition and stress (Gayton, Cielinski, Francis-Keniston, \& Hearns, 1989; Wrisberg \& Pein, 1992). The thinking is that rituals help improve performance because they mobilize motivational and regulatory states, either through improving concentration, creating physical readiness, or boosting confidence (Foster \& Weigand, \& Baines, 2006; Weinberg, Gould, \& Jackson, 1979).

This raises an important question of how pre-performance rituals differ from similar preparatory routines/habits. A wealth of research on pre-performance routines in athletes suggests that these behaviors also act as a regulatory mechanism for controlling arousal, attentional focus, and task expectations (e.g., Cohn, 1990; Singer, 2001). Despite serving similar regulatory functions, rituals are in fact considered distinct from habits or routines. Rituals possess a high level of rigidity and formality, with steps occurring in a fixed episodic sequence 
103 (Foster, Weigand, \& Baines, 2006; Rook, 1985; Rossano, 2012). In addition, unlike habits or

104 routines, which have measurable utility in achieving a goal-state and are context-dependent (e.g.,

105 Wood, Quinn, \& Kashy, 2002), rituals appear to have no direct function. The causal connection

106 between ritual and the attendant goal is less transparent than other instrumental behaviors like

107 habits, a distinction often referred to as the ritual stance versus instrumental stance (Hermann,

108 Legare, Harris, \& Whitehouse, 2013; Kapitány \& Nielsen, 2015, 2016; Legare, Wen, Herrmann,

$109 \&$ Whitehouse, 2015).

110 Consider the example of an Olympic athlete whose pre-game ritual is to place her shin

111 pads in a repeated manner from bottom-to-top. This fixed set of actions, if done properly, makes

112 her feel that she is ready to perform her best. But if she alters the sequence, placing pads instead

113 from top-to-bottom, she may feel the preparation is "off" and, thus, her performance will suffer.

114 Although the actions in this case are arbitrary, and the order of pad placement has no direct

115 impact on performance (i.e., the behavior lacking overt instrumental value), the sequenced

116 repetition of the ritual might leave the athlete feeling calm and prepared. In contrast, a pre-

117 performance routine might involve similar actions, but the element of scrupulously adhering to a

118 particular sequence falls away; sticking to the script is no longer imperative as it is during ritual

119 (Dulaney \& Fiske, 1994). Here the athlete's routine might entail putting on her pads, but without

120 feeling compelled to do the preparatory actions in any particular prescribed order. Thus, pre-

121 performance rituals possess a deep-level irrationality, but even still, they appear to promote

122 effective goal-pursuit. How does this happen? Recent experimental evidence from social and

123 cognitive psychology has begun to shed light on the underlying processes involved. 
For instance, it has been shown that activating superstitious concepts - irrational

127 cognitions frequently found in different rituals - leads to improved performance by making

128 people feel like luck is on their side, thereby boosting feelings of self-efficacy and confidence

129 (Damisch, Stoberock, \& Mussweiler., 2010; but see Calin-Jageman \& Caldwell, 2014 for a failed

130 direct replication of these effects). Like superstitious thinking, rituals may improve performance

131 by fostering personal confidence and positive performance expectations, which in turn, leads to

132 greater success on the ensuing task. This process may act like a placebo: If a person believes a

133 ritual will help their performance, then having that belief alone will increase the chances of 134 success. ${ }^{\mathrm{i}}$

A very recent set of studies demonstrated that people tend to perform better on a range of

136 tasks when engaging in an arbitrary ritual beforehand, but only when the actions are labeled as

137 ritual. The researchers found evidence that participants' improved performance was explained by

138 a reduction in self-reported anxiety (Brooks, Schroeder, Risen, Gino, Galinsky, Norton, \&

139 Schweitzer, 2016). It has long been inferred that rituals - particularly religious rituals - can act

140 as a palliative against anxiety and failure. Indeed, evidence suggests that the completion of

141 chunked and predictable action sequences of a personal ritual can act as a compensatory strategy

142 to help regain control when experiencing anxiety (Boyer \& Liénard, 2007; Hirsh, Mar, \&

143 Peterson, 2012; Norton \& Gino, 2014). But certain rituals may be better equipped than others for

144 this. For example, Reinvestment Theory (Masters, 1992; Masters \& Maxwell, 2008) suggests

145 that making relatively automated movements more consciously active could disrupt the

146 associated motor program. Given this, an effective ritual might be one that prevents against

147 reinvestment by relinquishing conscious control by automating predictable sequences (Jackson \& 148 Masters, 2006). 
But how do such arbitrary sequenced behaviors impact goal-regulation, performance, and

150

151

152

153

154

155

156

157

158

159

160

161

162

163

164

165

166

167

168

169

170

anxiety? What neuropsychological mechanisms underlie these types of rituals? To gain insight

into this puzzling regulatory process, we can consider how the underlying mechanisms of ritual

are driven by brain-based regulatory control, specifically the neural performance-monitoring system.

\section{Neural Performance Monitoring, the ERN, and Ritual}

As a candidate proximal mechanism underlying the ritual-performance link, we expect to see changes in neural performance-monitoring, especially when considering its involvement in tracking motivationally relevant performance outcomes. Here, we wondered whether ritual's regulatory function can be traced either to heightened performance-monitoring (an orienting to failure), or to reduced performance-monitoring (minimizing reactivity to failure).

Offering a test of these predictions, when a person experiences some sort of performance failure, they tend to exhibit a distinct neurophysiological response, which indicates that such failures are not only monitored but also responded to emotionally (Inzlicht \& Al-Khindi, 2012) and perhaps with personal distress (Hajcak \& Foti, 2008). A common neural correlate of this monitoring system is the error-related negativity (ERN), an electroencephalographic waveform believed to arise from the dorsal region of the anterior cingulate cortex (Bush, Luu, \& Posner, 2000; Dehaene, Posner, \& Tucker, 1994; Gehring, Goss, Coles, \& Meyer, 1993; Mathalon, Whitfield, \& Ford, 2003). As a generic, multi-modal signal of the performance-monitoring system, the ERN is thought to be related to reinforcement learning (Holroyd \& Coles, 2002) and conflict monitoring (Botvinick, Braver, Barch, Carter, \& Cohen, 2001; Yeung, Botvinick, \& Cohen, 2004), reflecting the discrepancy between an expected outcome and an actual outcome 
171 (Holroyd \& Coles, 2002). It emerges between 50 and 100 milliseconds after an error is 172 committed.

173 Importantly, recent work has shown that the ERN may reflect not only the detection of

174 errors, but also the affective and motivational salience of performance failure, error, and conflict

175 (e.g., Hajcak, Moser, Yeung, \& Simons, 2005; Hobson, Saunders, Al-Khindi, \& Inzlicht, 2014;

176 Inzlicht, Bartholow, \& Hirsh, 2015; Proudfit, Inzlicht, \& Mennin, 2013; Weinberg, Riesel, \&

177 Hajcak, 2012). According to this view, the signal strength of the ERN may partially reflect an

178 evaluative appraisal of error or response conflict, with differences in ERN magnitude mapping

179 onto the sensitivity to performance failure and regulatory control.

Facilitating effective control during performance, the ERN is thought to be involved in

181 the detection of conflict/error (e.g., Botvinick et al., 2001; Falkenstein, Hoorman, Christ, \&

182 Hohnsbein, 2002), the openness to experiencing aversive performance error (e.g., Legault \&

183 Inzlicht, 2013; Teper \& Inzlicht, 2013), and the affective or evaluative response to that

184 performance error (e.g., Bartholow, Henry, Lust, Saults, \& Wood, 2012; Hajcak \& Foti, 2008;

185 Saunders, Rodrigo, \& Inzlicht, 2016). Critical to the test of our current hypotheses, we can map

186 the differences in ERN activation onto the explanation of ritual's predicted regulatory function.

187 On the one hand, larger ERNs tend to reflect heightened performance and error monitoring (van

188 Veen \& Carter, 2002), an internally driven mechanism optimizing performance by signaling the

189 need for remedial control (Carter, Braver, Barch, Botvinick, Noll, \& Cohen, 1998). If rituals

190 evoke a sense of confidence and self-efficacy, then we should see an increase in performance-

191 monitoring with increased motivation to detect potential sources of failure (i.e., a larger ERN).

192 On the other hand, smaller ERNs tend to reflect a blunted affective response to personally

193 distressing information like errors and performance failures (Maier, Scarpazza, Starita, 
194 Filogamo, \& Làdavas, 2016), the opposite being expressed in people with anxiety disorders and

195 high trait anxiety/worry (Hacjcak, McDonald, \& Simons, 2003; Olvet \& Hajcak, 2009; Weinberg

196 \& Hajcak, 2011). If, as some evidence has suggested, rituals appear capable of reducing anxiety

197 and mitigating uncertainty, then it is equally plausible that ritual leads to a decrease in

198 performance-monitoring (i.e., a smaller ERN). A possible downside, of course, is that this type

199 of blunted neural evaluation of errors might end up hurting performance rather than helping it

200 (e.g., Hobson, Saunders, Al-Khindi, \& Inzlicht, 2014; Ridderinkhof et al., 2002).

\section{The Current Study}

202 Here, in our openly pre-registered experiment (https://osf.io/hcmkp/), we asked if even

203 arbitrary ritual can influence the ERN, and if so in which direction (amplified or muted ERN).

204 Do rituals regulate goal-directed performance by (i) improving regulatory control through

205 enhanced error/failure detection, or (ii) dulling the threat of personal failure? For support of (i),

206 we would expect that rituals would lead to heightened performance-monitoring, as shown by an

207 amplified ERN. For support of (ii) we would expect that rituals would lead to a reduction in

208 performance-monitoring, as shown by a muted ERN.

\section{Methods}

\section{Participants}

211 A power analysis using $G^{*}$ Power (Faul, Erdfelder, Lang, \& Buchner, 2007) was run to

212 determine sample size. Using a mixed, pre-post design and assuming the typical moderate effect

213 size in social psychology (i.e., $r=.21, d=.43$; Richard, Bond, \& Stokes-Zoota, 2001) and high

214 correlations between repeated measures typical of event-related potential (ERP) designs $(r=.60$

215 - .80; Olvet \& Hajcak, 2009a; Segalowitz, Santesso, Murphy, Homan, Chantziantoniou, \& Khan,

216 2010), we determined that a total sample size of 48 participants yields a power value of 0.90 for 
217 detecting the hypothesized within-between interaction. We therefore decided to stop data

218 collection between 50-60 participants to account for participant exclusions. In line with open

219 science practices, we pre-registered the experiment on Open Science Framework

220 (https://osf.io/hcmkp/), where we outline the question of the two possible explanations, the

221 associated predictions, and detailed procedures.

222 Fifty-nine participants were recruited from the University of Toronto Scarborough

223 Campus through introductory psychology courses and campus advertisements. All participants

224 were provided with a consent form and signed their written consent to participate. Eleven

225 participants were excluded from all analyses due to equipment/hardware malfunction $(n=3)$,

226 high EEG artifact rate $(>30 \% ; n=5)$, failure to understand task instructions $(n=1)$, and the

227 commission of too few errors to calculate reliable evoked potentials $(n=2)$. ERN calculations

228 were based on no fewer than five artifact-free error trials (Olvet \& Hajcak, 2009). Half of one

229 participant's data was excluded because they made too few errors in the second block of the in-

230 lab experiment (fewer than five). Their usable data was still entered into the mixed effects

231 models using MLM (more below; see Gueorguieva \& Krystal, 2004). This left us with a final

232 sample of 48 participants (35 females; mean age $=19, S D=1.48$ ). Across conditions (ritual

233 condition $n=22$, control condition $n=26$ ), participants were told that they could earn bonus

234 money based on how well they completed the task ( $\$ 10$ guaranteed, with a chance to earn a

235 bonus $\$ 10)$. However, regardless of how they performed, all participants received $\$ 15$ for

236 participating (as well as a course credit for those in introductory psychology courses). This

237 deception (in regards to monetary compensation) was used to ensure that participants were

238 motivated to perform at their best during the performance tasks. The University of Toronto

239 granted ethical approval to carry out the study on human participants within its facilities 
240 (protocol reference \#28411). Participants gave full written consent before the start of the

241 experiment.

\section{Procedures}

243 The experiment was comprised of an at-home and in-lab portion, lasting seven days in total.

244 Participants were randomly assigned to a ritual or control (non-ritual movement) condition. They

245 were told that the purpose of the study was to examine the mind-body connection and the effects

246 of physical movement on cognitive performance. Importantly, the purpose of the study was kept

247 vague in order to hold it constant across the two conditions and to control for study demand

248 characteristics.

In the ritual condition, participants were asked to learn and memorize a set of elaborate

250

251

252

253

254

255

256

257

258

259

260

261

262

263

264 ad-hoc action sequences (see Table 1 for specific steps of the ritualized actions). The operationalization of ritual consisted of these novel and arbitrary actions, which were meant to mirror the features of real-life rituals. These features included repeated and sequenced movements accompanied by a set of instructions that were prescriptive and rule-bound (for similar manipulations, see Norton \& Gino, 2013; Hobson, Gino, Norton, \& Inzlicht, in press). Importantly, the term ritual was never mentioned to participants, instead merely referring to the behaviors as action sequences; this was done to control for any prior beliefs participants may have had about rituals and the expectations of what rituals do to assist performance. Participants were provided with written instructions of the sequenced steps as well as a video model (https://osf.io/u2t75/) to help them follow along and commit the actions to memory.

Table 1.

Action sequences instructions

1. Place your hands flat on the table. Spread your fingers of your left hand and keep your fingers of your right hand together. Close your eyes, and take three slow deep breaths. 
2. Now switch: spread your fingers of your right hand and bring your fingers of your left hand together. Close your eyes, and take three slow deep breaths.

3. Place the backs of your hands on the table, close your eyes, take three slow deep breaths.

4. Make fists and turn your fists over so the top of your wrist is facing upwards and your thumbs are inwards towards each other. Close your eyes, take three deep breaths.

5. Bring your fists together at your chest, slowly raise them above your head, and as you do draw in a large inhale through your nose. Return your fists to your chest while drawing out an exhale through your mouth. Repeat this three times.

6. Bring your open hands together at your chest (palm to palm), slowly raise them above your head, and then bring them back to your chest. Repeat this three times.

7. With your palms together at your chest, interlock your fingers so that your dominant hand's thumb is over the non-dominant thumb (i.e., dominant thumb touching your chest) and raise your hands above your head. Return them to your chest. Repeat this three times.

8. Starting at your chest, bring your interlocked fists to your right shoulder and hold for three seconds. Bring your interlocked fists back to your chest and hold for another three seconds. Bring your interlocked fists to your left shoulder and hold for another three seconds. Return your fists to your chest and clap twice.

9. Rest your hands, palms facing towards each other on the table in front of you. Hold for three seconds. Close your eyes and pull your hands apart. With your index/pointer fingers, tap the table ten times.

10. You are now finished.

Table 1. The specific actions that were given to participants during the at-home portion of the study. The behaviors were precisely ritual-like with features mirrored real life rituals, including an emphasis on fixed episodic sequences and repetitive movements.

In the control (non-ritual movement) condition, participants instead completed a coordinated movement task in which they were instructed to move their arms/hands at different times to touch moving block images on the computer screen. The amount of time and movement involved was the same as with the ritual actions. The only difference was that the control movements were not sequenced or repeated (i.e., strictly non-ritualistic). We were careful in this control manipulation so that we could infer that any observed differences would be attributable to the particular ritual movements themselves, and not any other non-ritual features of the athome experience.

All participants were sent five email reminders, one per day, during the at-home portion and prompted to complete the questionnaire and tasks. On day 1 participants were recruited and 
301 introduced to the study and asked to complete a simple demographic questionnaire; on days 2-5

302 participants completed the main part of the at-home portion; on day 6 , participants received

303 feedback on their task performance over the past four days (more on this below); finally, on day

3047 participants were scheduled for the in-lab portion of the study.

305 For the first four days, participants in the ritual condition were asked to complete the

306 action sequences (following along with the model video for the first two days and then from

307 memory for the remaining time), while participants in the control condition did the same

308 randomized block touching task each day. Afterwards, all participants completed a short version

309 of a Stroop task programmed using Inquisit 4.06. The Stroop task (Stroop, 1935) is a canonical

310 inhibitory control task that reliably tracks executive function ability. It was used during the at-

311 home portion in this case because we wanted participants to complete a reaction-time task that

312 was similar to the task they would be completing in the lab, but still different in order to control

313 for practice effects. Using a different (though related) executive function task allowed us to

314 examine the ritual-performance link over the duration of the week-long experiment.

315 The Stroop task consisted of a series of colored words (red, green, blue, or yellow;

316 congruent and incongruent trials) or colored blocks (control trials), in which participants were

317 asked to identify the color in which each word was presented. Each trial consisted of a fixation

318 cross ('+') presented for $500 \mathrm{~ms}$, followed by the color word (block) presented for $200 \mathrm{~ms}$, with

319 a response window of $1000 \mathrm{~ms}$. Participants completed 84 trials, split equally with 28 congruent

320 trials, 28 incongruent trials, and 28 control trials. Last, participants responded to eight items on a

321 scale from 1 (strongly disagree) to 7 (strongly agree) asking how they felt about their

322 performance on the Stroop. The questions read, "I felt [item here] about my performance." The

323 items included: accomplished, confident, able to handle, mastery, anxious, calm, in control, and 
324 frustrated. For the purposes of the current investigation, we do not evaluate or discuss the results

325 of the at-home task and questionnaires.

On the final day of the at-home portion, all participants were sent an email containing

327 false performance feedback from the previous four days. The feedback consisted of a line graph

328 showing participants reaction-times and error rates broken down by day, in comparison to the

329 running overall average of the study. The plotted lines showed that participants had improved

330 over the week and had been performing above average. In reality, every participant in both the

331 ritual condition and control condition received identical feedback. This was done in order to

332 convince participants that their performance was improving over time, further incentivizing their

333 performance on the upcoming laboratory task.

334 To ensure high compliance among participants during the at-home portion of the

335 experiment, we reminded them that the full participation required completion of both the at-

336 home tasks as well as the in-lab component. Our aim was to get participants to complete the

337 ritual or control actions every day during the week, or as often as they possibly could. To help

338 with this, we also tracked the number of times participants logged into the at-home survey,

339 which included following the action instructions (and video for Days 1-3) and completing the

340 Stroop task. Additionally, the final question of each survey asked participants to confirm that

341 they completed the actions (ritual or control) as instructed. Because our experimental

342 manipulation relied on this longitudinal experience of the at-home portion of the study, to

343 include participants who failed to do the tasks only once (or not at all) would compromise the

344 manipulation of our independent variable. Four participants in total ( $n=2$ in the ritual condition,

$345 n=2$ in the control condition) showed low compliance and completed the at-home task only

346 once. They were excluded from completing the in-lab portion but still offered credit. Low 
347 compliance was also confirmed during a funnel debriefing at the end of the in-lab session, when

348 participants reported the number of times they completed both the survey and actions (either

349 ritual or control) over the course of the week. This revealed that most people did in fact follow

350 the instructions and completed the actions almost every day of the at-home component $(M=$

$3516.78)$.

352

After one week, participants came into the lab to complete the final portion of the study.

When they arrived, participants were seated in front of a computer station and prepared for EEG recording. Continuous recording EEG was used while participants performed two rounds of a speeded inhibitory control task in a dimly lit room set at a viewing distance of approximately 100 $\mathrm{cm}$ to the screen. Different inhibitory control and speeded reaction tasks have been shown to elicit a reliable ERN signal. The performance paradigm used here was a modified go/no-go task, which consisted of a two-alternative, forced-choice task, where participants were instructed to press the /key with the right-hand if they saw an M ("go") target, and to press the Z key with their left-hand if they saw a W ("nogo") target. Key assignment was set on a standard QWERTY format and responses recorded using a millisecond sensitive DirectIN keyboard (Empirisoft, New York, NY). The M letter served as the frequent stimuli (.80 probability of appearing) and the $\mathrm{W}$ letter served as the infrequent stimuli (.20 probability of appearing). This imbalance in stimuli presentation was to ensure that participants developed a prepotent response tendency towards the frequent M ("go") stimuli, thus making the infrequent W ("nogo") stimuli errorprone, with successful button-press requiring inhibitory control. Because the task was forcedchoice, both infrequent and frequent responses were recorded and analyzed. In the results section, we refer to the frequent and infrequent stimuli as low-conflict and high-conflict trials, 369 respectively. 
372 background and centered in the middle of the screen. The screen then remained blank until one

373 of the response keys (/ or Z) was pressed or until the maximum response window (500 ms) was randomly between 450 and 1,000 ms before the start of the next trial. An incorrect response was immediately followed by an "error" message in white font on the black background and lasting for $500 \mathrm{~ms}$ before proceeding to the next trial. given. Remember, peak cognitive performance = fast \& accurate." Participants first completed pay. Following this, they completed a total of 760 experimental trials, which were divided into 8 blocks of 95 trials and separated by self-paced rest periods in between. We used a pre/post within subjects experimental design, in which all of the participants first completed the first 4 blocks (i.e., pre-rounds), followed by the movement manipulation done once more in the lab, and then again the final 4 blocks (i.e., post-rounds; see Figure 1 displaying the in-lab experimental design).

Before beginning the pre-rounds, participants answered four motivated preparation questions, which asked them to think about and anticipate their upcoming performance (e.g., "How mentally prepared do you feel heading into the task?" and" How well do you expect to perform on this round?") on a 1 ("not prepared at all"; "not well at all") to 7 ("very prepared"; 
393 and used in subsequent analyses (Cronbach's $\alpha=.87$ ). After answering these questions,

394 participants completed 4 blocks of the pre-round trials.

After the pre-rounds, participants were asked to report their subjective experience of how

396

397

they felt during their performance using the same eight items from the at-home portion. Three questions asked about participants' specific emotional experience (anxious, calm, and frustrated), while the remaining five questions asked about their self-efficacy (control, accomplished, confident, handle, and mastery). Anxiety and frustration were reverse-scored and combined with calm to create an aggregate positive affect score (Cronbach's $\alpha=.86)$. Similarly, control, accomplished, confident, handle, and mastery were combined to create an aggregate score for self-reported efficacy (Cronbach's $\alpha=.94)$.

The actions manipulation was carried out in between the pre- and post-rounds.

Participants in the ritual condition were asked to complete the action sequences as they had memorized them over the course of the week, and to press the spacebar key once finished. Participants in the control condition completed the block touching task for the same amount of time. Afterwards, all participants completed the four motivated preparation questions like before. Participants then finished the final 4 blocks of the post-round trials, and again answered the same emotion and efficacy questions.

At the end of the performance task, participants in the ritual condition completed a set of questions that asked how they felt about their week-long experience in completing the action sequences. There were six items related to the ritual appraisal (ease, enjoyment, effort, special, meaningful, and powerful). We reverse scored effort and combined all the items (Cronbach's $\alpha$ $=.78)$ to create an index for positive ritual appraisal. Finally, participants in the ritual condition were asked to report how they felt about the experience of learning the action sequences over the 
416 course of the week. We recorded their open-ended answers for qualitative purposes. All

417 participants were then thanked and fully debriefed. 


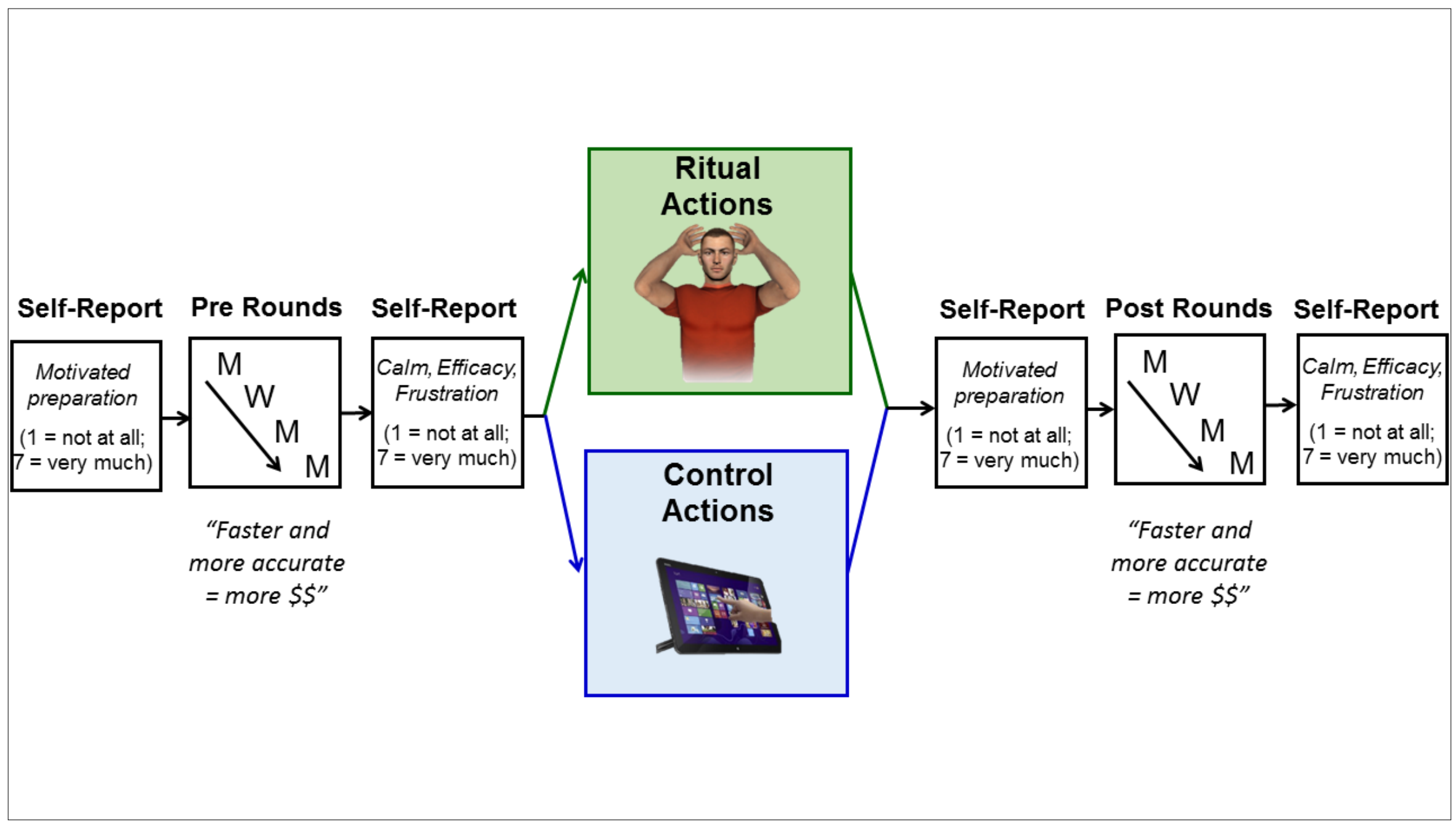

Fig. 1. A pre/post mixed experimental design for the in-lab portion of the study. Participants completed 380 pre-round trials, underwent the action manipulation (ritual versus control), and then completed 380 post-round trials. Motivated preparation and subjective experience (emotion and efficacy) were asked before and after each round. 
Neurophysiological recording and analysis. Continuous EEG was recorded during the

425

426

427

428

429

430

431

432

433

434

435

436

437

438

439

440

441

442

443

444

445

eight blocks of the executive function task using a stretch Lycra cap embedded with 32 tin electrodes (Electro-Cap International, Eaton, $\mathrm{OH}$ ). The scalp-electrode montage consisted of midline electrode sites (FPz, Fz, FCz, Cz, CPz, Pz, and Oz). The continuous EEG data were digitized using a sample rate of $512 \mathrm{~Hz}$, and electrode impedances were maintained below $10 \mathrm{k} \Omega$ during recording. EEG activity were amplified using an ANT Refa8 TMSi device (Advanced Neuro Technology, Enschede, The Netherlands). Offline, both sets of signals were referenced analyzed with Brain Vision Analyzer 2.0 (Brain Products GmbH, Munich, Germany).

The EEG data was digitally filtered offline between 0.1 and $15 \mathrm{~Hz}$ and the data corrected for vertical electro-oculogram artifacts (Gratton, Coles, \& Donchin, 1983). An automatic procedure was employed to detect and reject artifacts. The criteria applied were a voltage step of more than $25 \mu \mathrm{V}$ between sample points, a voltage difference of $150 \mu \mathrm{V}$ within $150 \mathrm{~ms}$ intervals, voltages above $85 \mu \mathrm{V}$ and below $-85 \mu \mathrm{V}$, and a maximum voltage difference of less than 0.50 $\mu \mathrm{V}$ within $100 \mathrm{~ms}$ intervals. These intervals were rejected from individual channels in each trial in order to maximize data retention. The EMG signal was filtered offline using a $28-500 \mathrm{~Hz}$ IIR bandpass and $60 \mathrm{~Hz}$ notch filter, then rectified using a moving average procedure with a time constant of $20 \mathrm{~ms}$ (Cacioppo, Tassinary, \& Bernston, 2007). EMG artifact rejection consisted of voltages above $100 \mu \mathrm{V}$ and below $-100 \mu \mathrm{V}$.

Using previous protocol for analyzing the ERN (e.g., Saunders, Rodrigo, \& Inzlicht, 2015), the continuous EEG was segmented into epochs that commenced $200 \mathrm{~ms}$ before the response and lasted for $800 \mathrm{~ms}$ post-response. The ERPs (both the correct-related negativity; CRN, and ERN) were averaged separately for each experimental condition (ritual versus 
446 control). The CRN and ERN were operationalized as the mean amplitude between 0 and $80 \mathrm{~ms}$ at

447 electrode FCz (e.g., Wiswede, Münte, \& Rüsseler, 2009). This time window was selected using

448 the collapsed localizers approach suggested by Luck and Gaspelin (in press) to deal with the

449 problem of multiple implicit comparisons inherent in ERP research. Though we used 0-80 ms

450 based on this approach, the results were no different when alternative time windows were used,

451 including 0 to $100 \mathrm{~ms}$. ERN calculations were based on no fewer than five artifact-free error

452 trials (Olvet \& Hajcak, 2009). EEG data were baseline corrected between -150 to -50 ms pre-

453 response.

454

455

456

457

458

459

460

461

462

463

464

465

466

467

468

Statistical analysis. All the analyses were conducted using multilevel modeling (MLM)

with the MIXED function in SPSS (v. 22.0). A 2-level multilevel model was used to account for within-subjects performance and ERN nested within individual participants while estimating a random intercept for each participant. We included all possible main effects and interactions in each model tested. We used an unstructured covariance matrix and the between-within method for estimating degrees of freedom. Effect sizes were estimated with semi-partial $R^{2},\left(\mathrm{R}_{\beta}\right.$; Edwards, Muller, Wolfinger, Qaqish, \& Schabenberger, 2008).

For the behavioral data (mean RTs and choice error rates), the effect of condition $(1=$ ritual, $-1=$ control $)$ was modeled as a function of round $(1=$ pre, $-1=$ post $)$ and conflict level $(1$ $=$ high conflict, $-1=$ low conflict). For the ERP and EMG analyses, the initial model was identical to the behavioral data, except conflict level was replaced by trial type. Here, trial type accounted for the correct-related negativity $(\mathrm{CRN})$ and error-related negativity $(\mathrm{ERN})$ ERPs $(1=$ $\mathrm{CRN},-1=\mathrm{ERN})$.

Behavioral Performance: choice error rates and mean RTs. 
469 All data are open and available on the Open Science preregistration site (osf.io/h64cz). We report 470 all measures, manipulations, and exclusions. Confirming the task's conflict manipulation, the 471 model indicated a large main effect of conflict, with participants generating higher error rates on 472 high-conflict trials $(M=20.16 \%, S E=1.13)$ than low-conflict trials $(M=0.72 \%, S E=1.13), b$ $473=-17.28, t(138)=-7.04, S E=2.46, p<.0001,95 \%$ CIs $[-22.14,-12.43], \mathrm{R}_{\beta}=.66$. There was also 474 a small, albeit non-significant effect of round, $b=4.13, t(138)=1.68, p=.095, S E=2.46,95 \%$ 475 CIs $[-0.73,8.98], R_{\beta}=.01$, such that participants tended to have lower error rates in the pre 476 rounds $(M=9.56 \%, S E=1.13)$ than the post rounds $(M=11.29 \%, S E=1.13)$. These analyses 477 confirm the high versus low conflict manipulation. There was no main effect of ritual, $b=0.30$, $478 t(138)=0.11, p=.92,95 \%$ CIs $[-5.25,5.85], \mathrm{R}_{\beta}=0.001$, nor was there a significant two-way interaction between ritual condition and round, $b=-0.69, t(138)=-0.21, p=.84,95 \%$ CIs [-7.28, $4805.91], R_{\beta}=0.001$. Together, these results suggest that the ritual manipulation had no effect on 481 error-rates.

Next, the same model was run with mean RTs. Again, the model indicated a large main 483 effect of conflict, with participants responding more slowly during high-conflict trials $(M=$ $414.44 \mathrm{~ms}, S E=7.42)$ than during low-conflict trials $(M=346.09 \mathrm{~ms}, S E=7.42), b=-65.48$, $t(138)=-9.33, S E=7.02, p<.0001,95 \%$ CIs $[-79.36,-51.60], \mathrm{R}_{\beta}=.75$. There was no effect of ritual condition, $b=1.33, t(138)=0.09, p=.93,95 \% \mathrm{CIs}[-29.81,32.47], \mathrm{R}_{\beta}=0.001$, nor of round, $b=-1.86, t(138)=-0.27, p=.79,95 \%$ CIs $[-15.75,12.02], \mathrm{R}_{\beta}=0.00$, and no two-way interaction between ritual condition and round, $b=-5.06, t(138)=-0.53, p=.60,95 \%$ CIs [23.92, 13.80], $\mathrm{R}_{\beta}=0.001$. 
492 experiment, the average break between blocks was roughly between $5 \mathrm{~s}$ and $15 \mathrm{~s}$. No participants

493 took longer than $45 \mathrm{~s}$ to $60 \mathrm{~s}$. Future research should take this into consideration as it is important

494 to assess the role of fatigue effects related to task performance across multiple trials.

495 Table 2 contains all the descriptive data for behavioral, self-report, and EEG measures.

496 Theses analyses show that all participants were faster and more accurate in the low-conflict

497 trials. However, there were no differences in performance between ritual and control conditions, 498 suggesting that the ritual had no impact on behavioral performance.

\section{ERN Data}

500 We next tested our main hypothesis to examine whether arbitrary ritual impacts the ERN 501 either by increasing performance-monitoring or decreasing performance-monitoring. To do this, 502 the effect of condition on the error-related ERPs (ERN and CRN) was examined. The ERP data 503 (i.e., the ERN and CRN while including the factor of trial type in the model; see above) was 504 considered. The model output revealed evidence of a reliable ERN as indicated by a more 505 negative ERP amplitude in response to erroneous $(M=-2.65 \mu \mathrm{V}, S E=0.86)$ than correct $(M=$

$5064.26 \mu \mathrm{V}, S E=0.78)$ responses, $b=10.08, t(46)=6.27, S E=1.61, p<.0001,95 \%$ CIs [6.84,

507 13.31], $\mathrm{R}_{\beta}=.63$. This was qualified by a significant two-way interaction between round and trial 508 type, $b=-5.05, t(46)=-3.27, S E=1.55, p=.002,95 \%$ CIs $[-8.16,-1.94], \mathrm{R}_{\beta}=.14$, indicating 509 that the difference between ERN and CRN amplitudes was lessened in the post rounds $\left(M_{E R N}=\right.$ -

$\left.5101.73 \mu \mathrm{V}, M_{C R N}=3.77 \mu \mathrm{V}\right)$ compared to the pre rounds $\left(M_{E R N}=-3.57 \mu \mathrm{V}, M_{C R N}=4.74 \mu \mathrm{V}\right)$, an

511 effect consistent with past work on the neural correlates of fatigue (Boksem, Meijman, \& Lorist, 512 2006; Inzlicht \& Gutsell, 2007).

513 Critically, this two-way interaction was subsumed under a three-way interaction, where

514 the interaction between round and trial type was moderated by our manipulation of ritual 
515 condition, $b=4.48, t(46)=2.14, S E=2.09, p=.037,95 \%$ CIs $[0.27,8.69], \mathrm{R}_{\beta}=.09$. Figure 2

516 displays the ERP and topographical graphs ${ }^{\text {ii }}$. These show a relatively large reduction in the post

517 rounds compared to the pre rounds for participants in the ritual condition. It appears, therefore,

518 that a dampened ERN in the ritual condition offers support for the hypothesis that ritual

519 decreases performance-monitoring, but without hindering overall performance

520 These analyses were followed up with a series of simple effects tests. First looking at

521 participants in the ritual condition, the model revealed that during error trials, the ERN amplitude

522 was significantly reduced (i.e., less negative) in the post rounds $(M=-1.22 \mu \mathrm{V}, S E=1.30)$

523 compared to pre rounds $(M=-4.87 \mu \mathrm{V}, S E=1.70), t(46.83)=2.24, p=.03, d=0.51$. Moreover,

524 opposite to the this pattern, it was found that during correct trials, the CRN amplitude was

525 significantly less positive in the post rounds $(M=3.81 \mu \mathrm{V}, S E=1.16)$ compared to the pre

526 rounds $(M=5.21 \mu \mathrm{V}, S E=1.19), t(45.30)=2.95, p=.005, d=0.25$. The same comparisons

527 done with participants in the control condition showed that the ERN amplitudes were no

528 different in the pre rounds $(M=-2.26, S E=1.56)$ compared to the post rounds $(M=-2.23, S E=$

529 1.17), $t(45.79)=0.02, p=.98, d=0.004$. The $\mathrm{CRN}$ amplitudes were also no different during pre

$530(M=4.28, S E=1.10)$ and post rounds $(M=3.73, S E=1.07), t(45.05)=1.26, p=.21, d=0.10$.

531 The simple effects comparing ERNs/CRNs within pre and post rounds revealed no differences

532 between ritual and control conditions. CRNs for both conditions were no different for both pre

533 rounds $(t(46)=0.58, p=.57, d=0.17)$ and post rounds $(t(46)=0.04, p=.97, d=0.01)$. There

534 was also no differences in ERNs for both conditions in pre rounds $(t(46)=1.13, p=.26, d=$

$5350.33)$ and post rounds $(t(45.86)=0.58, p=.57, d=0.17)$.

536 Research typically indicates that a lower ERN relates to poor performance (e.g., Hobson

537 et al., 2014), but this was not the case here. Looking at the ritual conditions separately, a 
538 dampened ERN was generally associated with worse performance, as revealed in higher error-

539 rates, but only in the control condition (pre round: $r(26)=.34, p=.09$; post round: $r(26)=.47, p$

$540=.015$ ). This link did not hold for participants in the ritual condition (pre round: $r(22)=.15, p=$

541.51 ; post round: $r(21)=.24, p=.29)$. These results suggest that the effect of a muted ERN after

542 completing the ritual was somewhat independent of task performance. Though this is not directly

543 tested here, it is possible that the ritual in this case facilitated performance by impacting the

544 emotional component of the action-monitoring system (dulling the neuroaffective response to

545 errors) without sacrificing features of conflict-monitoring and cognitive performance. However,

546 more work is needed to directly test this hypothesis.

547 Altogether, the evidence from the above analyses offers modest support for the

548 hypothesis that arbitrary, ad-hoc ritual (despite not being called ritual) reduces performance-

549 monitoring, muting the neuroaffective response to distressing performance failures during task

550 performance. 
A.

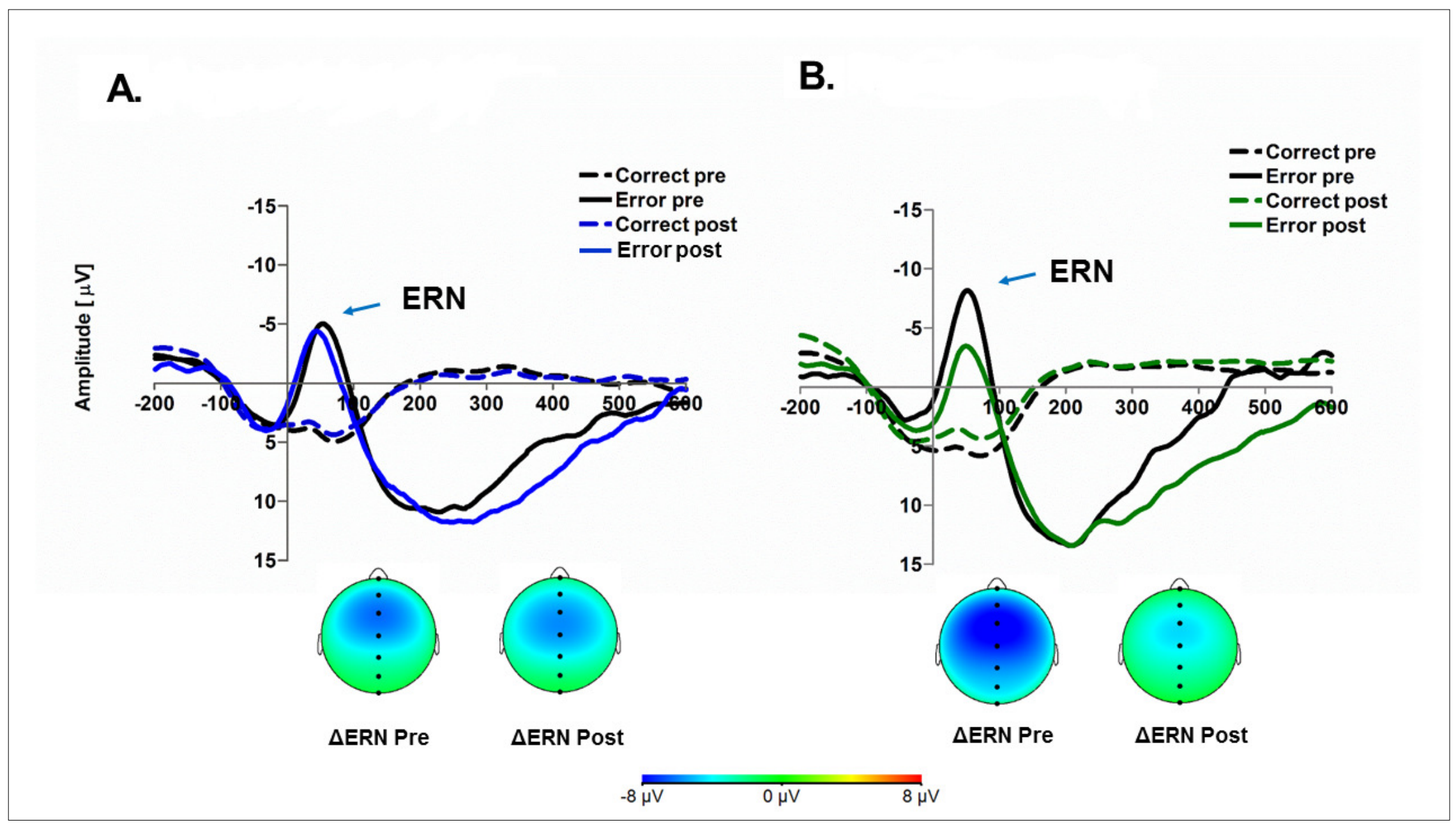

B.

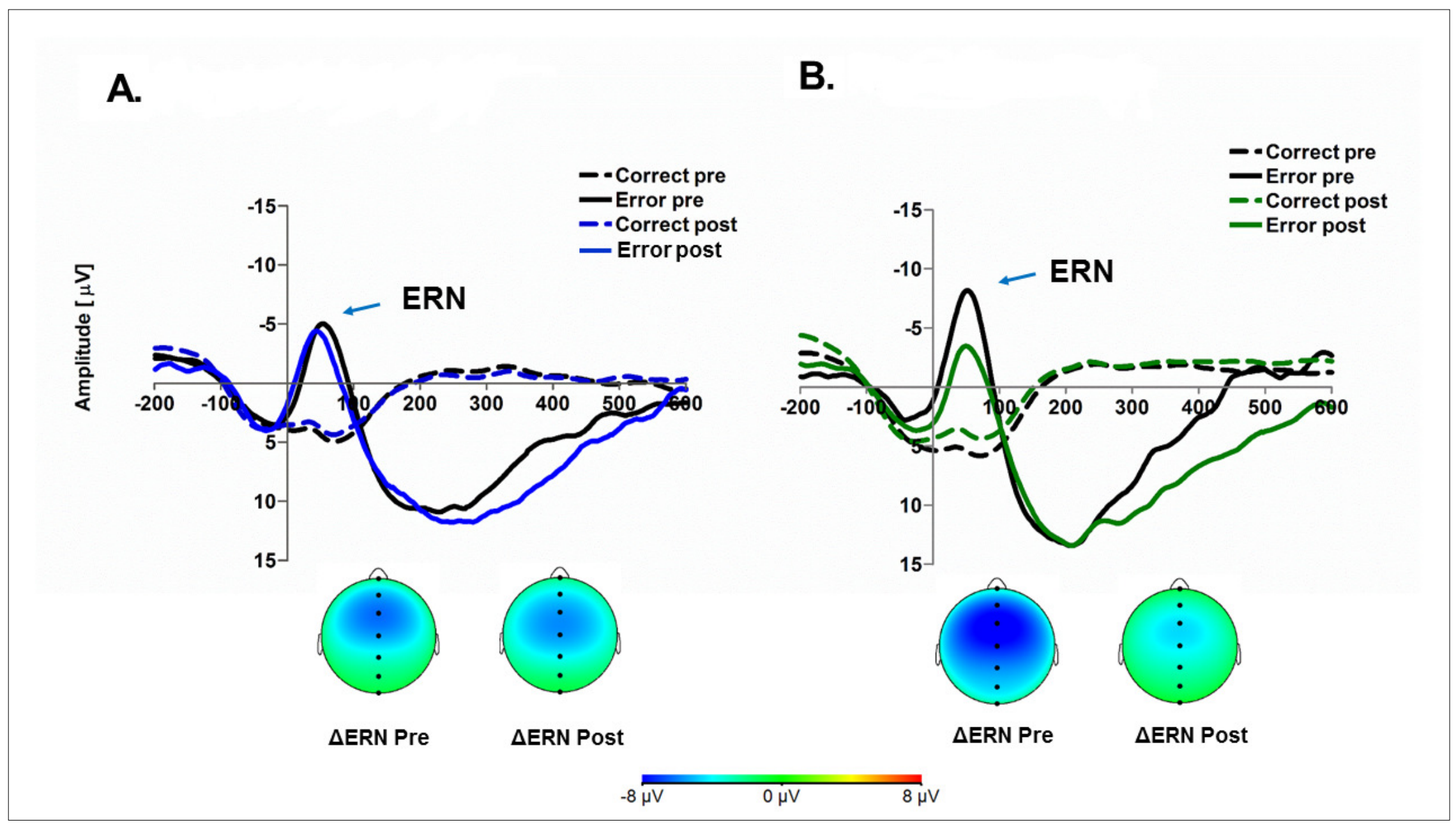

Fig. 2. Error-related ERPs as a function of condition assignment $(A=$ control condition; $B=$ ritual condition), trial type (correct $=$ dotted lines; errors $=$ solid lines) and manipulation time-point (pre-rounds $=$ black lines; post-round $=$ colored lines).

Spline head maps: Scalp distributions of the $\triangle E R N$ (difference wave $=E R N-C R N)$ for mean activity $(0-80 \mathrm{~ms})$ as a function of condition assignment and time-point. 
557

558

559

560

561

562

563

564

565

566

567

568

569

570

571

572

573

574

575

576

577

578

579

580

\section{Self-Report Data}

Self-reported emotion, efficacy, and motivation. Three separate models were run on the self-report data. The trial-type factor (error versus correct response) was removed from the model as we had no self-report data at this level of analysis. First, for positive emotion ratings, there was no main effect of condition, $b=-0.08, t(45)=-0.21, S E=0.40, p=.84,95 \%$ CIs [$0.89,0.72]$, no main effect of round, $b=0.003, t(45)=0.01, S E=0.21, p=.99,95 \%$ CIs $[-0.43$, 0.43], and no interaction, $b=0.10, t(45)=0.33, S E=0.32, p=.75,95 \%$ CIs [-0.53, 0.74]. After completing the pre-rounds and post-rounds, there was no difference in positive emotions felt in both the ritual condition $\left(M_{\text {pre-rounds }}=4.79 ; M_{\text {post-rounds }}=4.68\right)$ and control condition $\left(M_{\text {pre-rounds }}=\right.$ 4.77; $M_{\text {post-rounds }}=4.77$ ). Similar patterns were found with efficacy ratings, with no main effect of condition $(b=0.29, t(45)=0.76, S E=0.37, p=.76,95 \%$ CIs $[-0.46,1.03]$, no main effect of round, $b=-0.18, t(45)=-0.94, S E=0.19, p=.35,95 \%$ CIs $[-0.56,0.20]$, and no interaction, $b=$ $0.09, t(45)=0.33, S E=0.28, p=.74,95 \%$ CIs $[-0.47,0.66]$. Participants reported feeling no difference in efficacy in both the ritual condition $\left(M_{\text {pre-rounds }}=4.65 ; M_{\text {post-rounds }}=4.73\right)$ and control condition $\left(M_{\text {pre-rounds }}=4.27 ; M_{\text {post-rounds }}=4.45\right)$. Finally, the same pattern was found for ratings of motivated preparation, with no main effect of condition $(b=0.42, t(45)=1.52, S E=0.28, p=$ $.13,95 \%$ CIs $[-0.13,0.98]$, no main effect of round, $b=0.20, t(45)=1.07, S E=0.19, p=.29$, $95 \%$ CIs $[-0.18,0.58]$, and no interaction, $b=-0.25, t(45)=-0.89, S E=0.28, p=.38,95 \%$ CIs [0.81, 0.31]. Again, participants' motivated preparation was no different in both the ritual condition $\left(M_{\text {pre-rounds }}=5.08 ; M_{\text {post-rounds }}=5.13\right)$ and control condition $\left(M_{\text {pre-rounds }}=4.90 ; M_{\text {post-rounds }}\right.$ $=4.70$ ). These analyses indicate that participants from both conditions self-reported no changes in affect/motivation going from time 1 to time 2. 


\begin{tabular}{lccccc}
\hline & \multicolumn{2}{c}{ Control condition } & & \multicolumn{2}{c}{ Ritual condition } \\
\cline { 2 - 3 } \cline { 5 - 6 } Dependent variable & Pre-rounds & Post-rounds & & Pre-rounds & Post-rounds \\
\hline Positive emotion & $4.76_{\mathrm{a}}(1.34)$ & $4.76_{\mathrm{a}}(1.45)$ & & $4.86_{\mathrm{a}}(1.24)$ & $4.73_{\mathrm{a}}(1.48)$ \\
Efficacy & $4.27_{\mathrm{a}}(1.30)$ & $4.47_{\mathrm{a}}(1.42)$ & & $4.65_{\mathrm{a}}(1.27)$ & $4.68_{\mathrm{a}}(1.02)$ \\
Motivated preparation & $4.90_{\mathrm{a}}(0.84)$ & $4.70_{\mathrm{a}}(0.97)$ & & $5.08_{\mathrm{a}}(1.01)$ & $5.13_{\mathrm{a}}(1.03)$ \\
Positive ritual appraisal & & & & \multicolumn{2}{c}{$5.33(0.99)$} \\
& & & & & \\
Low-conflict error rate $(\%)$ & $1.0_{\mathrm{a}}(0.94)$ & $0.58_{\mathrm{b}}(0.65)$ & & $0.84_{\mathrm{a}}(1.12)$ & $0.46_{\mathrm{b}}(0.78)$ \\
High-conflict error rate $(\%)$ & $18.42_{\mathrm{a}}(12.17)$ & $21.86_{\mathrm{b}}(14.58)$ & & $18.12_{\mathrm{a}}(12.83)$ & $22.25_{\mathrm{a}}(15.06)$ \\
Low-conflict reaction time & $352.96_{\mathrm{a}}(52.22)$ & $343.54_{\mathrm{b}}(55.60)$ & & $350.50_{\mathrm{a}}(37.81)$ & $337.35_{\mathrm{b}}(32.91)$ \\
High-conflict reaction time & $417.31_{\mathrm{a}}(58.69)$ & $410.38_{\mathrm{a}}(66.67)$ & & $415.98_{\mathrm{a}}(54.46)$ & $414.11_{\mathrm{a}}(59.52)$ \\
& & & & \\
ERN $(\mu \mathrm{V})$ & $-2.26_{\mathrm{a}}(6.07)$ & $-2.23_{\mathrm{a}}(5.97)$ & & $-4.87_{\mathrm{a}}(7.97)$ & $-1.22_{\mathrm{b}}(6.09)$ \\
CRN $(\mu \mathrm{V})$ & $4.27_{\mathrm{a}}(5.61)$ & $3.73_{\mathrm{a}}(5.46)$ & & $5.21_{\mathrm{a}}(5.58)$ & $3.81_{\mathrm{b}}(5.44)$ \\
$\Delta$ ERN $($ ERN-CRN) & $-6.54_{\mathrm{a}}(7.55)$ & $-6.05_{\mathrm{a}}(5.09)$ & & $-10.08_{\mathrm{a}}(7.55)$ & $-5.07_{\mathrm{b}}(5.20)$ \\
\hline
\end{tabular}

582

583

584

585

586

587

588

589

590

591

592

593

594

595

596

597

Table 2. Means (SD) for self-reported subjective experience, performance on the inhibitory control task, and electroencephalography (EEG) measures. Means across rows (within each condition) with different subscripts differ significantly at $p<.05$ (two tailed).

\section{Exploratory Analyses: Self-Report Emotion and Appraisals, ERN, and Performance}

We next conducted a set of exploratory analyses that were planned after the initial pre-

registration, namely exploring the relationship between our different observed variables: ERN, performance, and self-reported emotion/motivation. We also examined participants' general positive appraisal of the ritual (it is important to note that since the questions were only given to participants in the ritual condition, these findings apply only to this group). Table 3 shows the correlations between all variables. For ease of interpretability, all variables (with exception to the positive ritual appraisal) were coded as a difference-score to represent the change in value from pre- to post-rounds (e.g., Efficacy $=$ efficacy $_{\text {post }}$ - efficacy $\left.{ }_{\text {pre }}\right)$. In this case, a more positive value would indicate an increase in efficacy form the pre- to the post-rounds. The correlations indicate that the ERN/ $\triangle \mathrm{ERN}$ were unrelated to the self-report variables. 

associated with both self-report and performance (but not ERN). Specifically, participants who evaluated the ritual experience as positive (i.e., meaningful, special, easy, etc.) were more likely:

601

602

603

604

605

606

607

608

609

610

611

\begin{tabular}{lcccccccc}
\hline Measure & 1 & 2 & 3 & 4 & 5 & 6 & 7 & 8 \\
\hline 1. Motivated preparation & - & $.25^{\dagger}$ & .02 & .00 & .22 & -.21 & -.20 & $.38^{\dagger}$ \\
2. Positive affect & & - & $.51^{* *}$ & $-.27^{\dagger}$ & $.28^{\dagger}$ & -.13 & -.11 & $.43^{*}$ \\
3. Efficacy & & & - & $-.46^{* *}$ & $.34^{*}$ & -.05 & -.03 & $.41^{\dagger}$ \\
4. Error rate & & & & - & $-.73^{* *}$ & .06 & .02 & $-.53^{*}$ \\
5. Reaction-time & & & & & - & -.22 & -.08 & $.68^{* *}$ \\
6. ERN & & & & & - & $.96^{* *}$ & -.05 \\
7. ERN & & & & & & - & -.06 \\
8. Ritual appraisal & & & & & & - \\
\hline
\end{tabular}

to feel better prepared heading into the post rounds; to commit fewer errors and respond more

cautiously with longer RTs in the post rounds; and to report feeling more positive affect and

greater efficacy after completing the post-rounds. Thus, it appears that the people who benefited

from improved performance and heightened positive emotion/efficacy, were the ones who

believed the actions actually had some sort of a positive impact on their performance.

These findings offer some clues to how rituals operate in the real-world and explain why

these puzzling behaviors persist. Often the compulsion to do the ritual (and to do it properly) is

because the person believes, for whatever reason, the ritual works to help achieve a desirable

outcome. As this placebo effect builds across time, ordinary gestural actions start to develop

personal meaning, transforming mere actions into a symbolic ritual practice.

Table 3.
612

613

614

615

616

617

Table 3. Correlations between subjective experience of emotion/motivation, performance errorrates/reaction times, error-related neural monitoring, and positive ritual appraisals. All variables represent the difference scores accounting for changes from pre-rounds to post-rounds. $* * p<.01 . * p<.05 .{ }^{\dagger} p<.10$.

\section{Exploratory Analyses: Open-ended responses}


of the action sequences and their experience with them over the course of the week. Again, these responses were only collected for participants in the ritual condition. To investigate the content of the responses, we used the Linguistic Inquiry and Word Count 2007 (LIWC) software. LIWC is a text analysis program that counts words in a string of text and places them into preset psychological categories (Pennebaker, Chung, Ireland, Gonzales, \& Booth, 2007). We looked at the four relevant LIWC categories, which included affective language (positive and negative valenced words) and self- versus other-directed language (self-referential and social words). One participant was not included in the analyses because they did not write anything in the response. Analyses revealed that participants used more self-referenced words $(M=10.98 \%, S D=14.35)$ than other-referenced words $(M=2.03 \%, S D=11.74), t(20)=8.00, p<.0001$, suggesting the ritual was a personal experience rather than a social one. Also, aligning with the above selfreport findings, participants reported more positive emotion words $(M=3.84 \%, S D=11.07)$ than negative emotion words $(M=0.44 \%, S D=0.73), t(20)=4.39, p<.0001$. make participants feel a greater sense of calm during their performance. Interestingly, the feature of sequenced action repetition was frequently mentioned. For instance, one participant wrote: “ $I$ was able to observe that the repetition of activities somehow improved the completion of the tasks. I think that maybe completing the set of actions helped me feel a little more focused and calmed." Another participant wrote: "Over the week, and in the study, completing the actions before beginning the task helped calm myself and make me feel in control for some reason." The 
640 doing the action sequences at home, it made me more focused on my studies for the upcoming

641 midterms."

642 Tying this back into ritual's effects on reduced performance-monitoring, a dampened

643 ERN signal could be related to participants' belief or perception that the ritual mitigated anxiety,

644 and in turn, benefitted their overall performance. Taken together, across all the findings we find

645 support that even arbitrary action sequences resembling ritual minimize performance-monitoring

646 by dulling the neurophysiological reactivity to distressing self-generated failures, while still

647 maintaining adequate performance.

648

\section{Discussion}

649

With a multiday experimental design using arbitrary and novel ritual-like actions, we

650

offer causal evidence that performance rituals impact the neural regulatory system. Specifically,

651 in a pre-registered experimental design, we put forward the question: Is ritual's regulatory

652 function driven by increases in performance-monitoring and motivated control (i.e., amplified

653 ERN), or by decreases in performance-monitoring, which might relate to error-related distress

654 (i.e., muted ERN)? The current findings offer more support for the latter: Arbitrary ritual mutes

655 the brain-based system attuned to the neuroaffective experience of regulatory failure. Despite

656 decreases in performance-monitoring, however, the reduced ERN did not predict worse

657 performance as it did in the control condition, a dissociation suggesting that ritual may be

658 capable of regulating performance distress without sacrificing controlled behavior.

659 Indeed, recent research shows that a decrease in performance-monitoring is consistent

660 with the experience of a person being less affected by self-generated errors and other sources of

661 uncertainty/conflict. In the performance-monitoring domain, this pattern of a reduced ERN in

662 response to performance failure is also consistent with other research highlighting the 
663 neurophysiological regulation of distress, anxiety, and uncertainty (e.g., Hajcak, McDonald, \& 664 Simons, 2004; Jackson, Nelson, \& Hajcak, 2016; Tullett, Kay, \& Inzlicht, 2014). Further, the 665 notion that rituals act as a palliative (consistent with a dampened ERN) aligns with similar 666 research showing that religious beliefs act as a buffer against the pang of anxiety felt from self667 generated failure (e.g., Good, Inlzlicht, \& Larson, 2015; Inzlicht, McGregor, Hirsh, \& Nash, 668 2009; Inzlicht \& Tullett, 2010). Given the degree of overlap between ritual and religion - i.e., 669 religion believed to be born out of the behaviors of early human ritual - it is reasonable to expect 670 they share a common neural basis.

671 One implication of a general decrease in performance-monitoring is that since the 672 detection of errors signals the need to initiate remedial action for better future performance, 673 being less perturbed by failure (either through religious belief or ritual practice) could be 674 considered maladaptive in certain contexts (e.g., Inzlicht et al., 2015; Inzlicht \& Legault, 2014). 675 As noted, however, this is not the case here. The fact that we do not see performance deficits 676 linked to a reduced ERN might mean that ritual is capable of modulating performance677 monitoring to ensure that an appropriate amount of error-related distress is still felt (but not too 678 much). In other words, a ritual could help a person during performance find the anxiety sweet679 spot that appears ideal for generating effective control (Yerkes \& Dodson, 1908).

680 These findings complement the recent set of studies by Brooks et al. (2016) who found 681 that arbitrary one-off rituals improve performance by reducing anxiety. The current findings 682 build off this work in two main ways: First, we investigated rapid, online brain activity of the 683 performance-monitoring system in response to the gold-standard of cognitive performance, a 684 classic executive function task (e.g., Baddeley, 1996; Diamond, 2013). Second, we 685 operationalized ritual as a week-long practice (versus done once in the lab) involving regular 
686 repetition, an important feature of real-life ritual (Legare \& Souza, 2012). Indeed, our related

687 work has shown that repetition is necessary in order for ritual to exert an influence on behavior 688 (Hobson, Norton, Gino, \& Inzlicht, in press).

689 More broadly, the growing interest in the experimental study of ritual (e.g., Lang, Krátký, 690 Shaver, Jerotijevic, \& Xygalatas, 2015; Schjoedt, Sørensen, Nielbo, Xygalatas, Mitkidis, \& 691 Bulbulia, 2013; Vohs, Wang, Gino, \& Norton, 2013; Wen, Herrmann, \& Legare, 2016) offers 692 converging evidence that the even the most minimal and basic ritual actions (behaviors stripped 693 of all personal and cultural meaning) can have predictive effects on brain and behavior. The 694 value of such an empirical approach is that it can help both researchers and applied practitioners understand how performance rituals are created and for which purpose; that is, to understand the psychological processing that is involved as a ritual develops from being mere stereotyped 697 actions to an important practice apart of one's identity. experience, for instance, by ascribing meaning to meaningless actions (Kapitány \& Nielsen, 2015) and by automating predictable sequences over time. Though the ritual actions were

701

702

703

704

705

706

707 708 initially framed as arbitrary, they likely developed a sense of purpose over the duration of the week. As hinted at in the self-report data, perhaps participants began to attribute their own personal meaning to the actions, making the connection between the completion of the ritual and achievement on the at-home task. The frequent practice of the actions would have also automated the motor sequence, which gets back at the idea of reinvestment and the extent to which conscious processing during a task disrupts motor performance (e.g., Masters, 1992).

Rituals are comprised of overlearned, predictable action sequences that are easily automated with frequent practice, and as a result, may be useful in terms of preventing unwarranted conscious 
709 motor control - "reinvestment" - before and during performance (for a similar argument see

710 Jackson \& Masters, 2006). Thus, to the extent that seemingly arbitrary movements facilitate

711 effective performance, certain rituals could over time become a functional tactic utilized by a

712 performer in contexts where reinvestment could occur.

\section{Limitations and future directions}

First, the evidence in support of ritual's palliative function comes mostly from ERN differences. Although we found arbitrary ritual dulled the neuroaffective system in response to error, there were no changes in self-reported affect to indicate that ritual made people consciously feel less anxious. Thus, it remains an open question whether ritual's effects on a reduced ERN is related to anxiety regulation per se. It is possible that the reduced ERN corresponded to a psychological change independent of negative affect; this explanation should be weighed equally seeing that the affect-ERN link is not necessarily a universally accepted idea (e.g., Moser, Moran, Schroder, Donnellan, \& Yeung, 2013). Similarly, although participants’ performance on the inhibitory control task tended to become worse from pre to post, it did so for both groups. It appears then that ritual impacts the neural regulatory system, primarily the rapid emotion-based processing that occurs prior to conscious error awareness. Despite this, we find no effect of ritual on actual performance, which lies in contrast to the notion that one of the functions of this style of preparatory ritual is to facilitate effective task performance. Together it

727 suggests that the current findings should be interpreted with some caution. To more fully understand ritual's regulatory basis, more work is needed (survey, behavioral, and neuro) to determine when ritual impacts behavior and how this relates not only to underlying neurophysiology, but to the subjective experience of anxiety and motivated performance on a task. For instance, are there certain rituals in real life that are more likely to impact performance, 
732 and furthermore, are the rituals that fail to have an effect still carried out by the practitioner?

733 Why?

Second, the altered performance-monitoring in post-rounds for the ritual condition

735

736

737

738

739

740

741

742

743

744

745

746

747

748

749

750

751

752

753

754 occurred by a combination of a reduced (i.e., less negative) ERN and enhanced (i.e., more negative) CRN. Thus, ritual's observed effects may not be exclusively a result of a dulled response to error (ERN), but a combination of an altered response to both errors and correct responses (both ERN and $\mathrm{CRN}$ ). An enhanced $\mathrm{CRN}$ can occur when there is greater amount of conflict in the stimulus-response association, or when uncertainty in performance is high (Pailing \& Segalowitz, 2004; Scheffers \& Coles, 2000). In clinical and health research, this type of reversal pattern in ERN/CRN is thought to be an indication of a global disruption in performance-monitoring (e.g., Pietschmann, Simon, Endrass, \& Kathmann, 2008) and has been found particularly in cases of schizophrenia (Mathalon, Fedor, Faustman, \& Ford, 2002) and in aging adults (Endrass, Schreiber, \& Kathmann, 2012). Of course, it is unclear why we found this type of reduced dissociation patterning after the enactment of ritual. Whether ritual might actually hinder overall performance-monitoring is a question that cannot be addressed with the present data but should be investigated more thoroughly in future replications.

Third, returning to the pre-manipulation differences in ERN amplitude, we can see in Figure 2 that the ritual group's pre-round ERN appears much larger than that of the control group, which could account for the muted ERN effect in the ritual condition. However, as indicated in the analyses, the pre-manipulation ERN differences in the ritual condition did not differ statistically, making it difficult to disambiguate the driving factors leading to the observed changes. Given the multiday experience of the ritual manipulation at home, it is possible that participants experienced a boost in performance-monitoring at the start of the lab task. 

observed effects. Different rituals are made up of different physical movements. For instance,

757 think about how a wedding ritual looks physically different than a funeral ritual. The physical

758 features that we used to create the arbitrary ritual (i.e., slow, deliberate movements) had a

759 meditative and calming feel to them, which involved frequent interval breathing. The muted

760 ERN could be attributed to a physical state of relaxation as opposed to the ritual movements

761 themselves. If the actions were faster and more action-oriented, like the pre-performance ritual of

762 a pumped-up athlete or musician, then it is possible that we would have seen the opposite pattern

763 of effects and an increase in performance-monitoring. We should therefore be cautious in

764 generalizing the current findings to fit all types of rituals.

\section{Conclusion}

766

Taken together, the current experiment offers causal evidence of the psychological and

767

768

769

770

771

772

773

774

775

776

777

778 neural basis of arbitrary ritual actions and their associated regulatory function. Though rituals might appear on the surface to be wasteful for expended energy and time, the presence of rituals in different performance contexts suggests they are critical to self-regulation and goal attainment. Here we offer preliminary support for the hypothesis that even an arbitrary ritual acts as a palliative by dulling the neural response to performance failure.

Acknowledgements We thank B. Saunders, H. Lin, N. Brown, Z. Francis, A. Ferguson, \& L. Zuber for helpful comments. 


\section{References}

Baddeley, A. (1996). Exploring the central executive. The Quarterly Journal of Experimental Psychology, 49, 5-28.

Bartholow, B. D., Henry, E. A., Lust, S. A., Saults, J., \& Scott, W. P. K. (2012). Alcohol effects on performance monitoring and adjustment: Affect modulation and impairment of evaluative cognitive control. Journal of Abnormal Psychology, 121, 173-186.

Boksem, M. A., Meijman, T. F., \& Lorist, M. M. (2006). Mental fatigue, motivation, and action monitoring. Biological Psychology, 72, 123-132.

Botvinick, M. M., Braver, T. S., Carter, C. S., Barch, D. M.,\&Cohen, J. D. (2001). Evaluating the demand for control: anterior cingulate cortex and crosstalk monitoring. Psychological Review, 108, 624-652.

Boyer, P., \& Liénard, P. (2006). Precaution systems and ritualized behaviors. Behavioral and Brain Sciences, 29, 635-641.

Bregmen, P. (2010). The value of ritual in your workday. Harvard Business Review, https://hbr.org/2010/12/the-value-of-ritual-in-your-wo/.

Brooks, A. W., Schroeder, J., Risen, J., Gino, F., Galinsky, A. D., Norton, M. I., \& Schweitzer, M. E. (2016). Don't stop believing: Rituals improve performance by decreasing anxiety. Organizational Behavior and Human Decision Processes

Bush G., Luu P., Posner M. I. (2000). Cognitive and emotional influences in anterior cingulate cortex. Trends in Cognitive Science, 4, 215-222.

Cacioppo, J. T., Tassinary, L. G., \& Berntson, G. (Eds.). (2007). Handbook of psychophysiology. Cambridge, UK: Cambridge University Press. 
801 Carter, C. S., Braver, T. D., Barch, D. M., Botvinick, M. M., Noll, D., \& Cohen, J. D. (1998).

802 Anterior cingulate cortex, error detection, and the online monitoring of performance.

$803 \quad$ Science, 280, 747-749.

804 Czech, D. R., Ploszay, A. J., \& Burke, K. L. (2004). An examination of the maintenance of

805 preshot routines in basketball free throw shooting. Journal of Sport Behavior, 27(4), 323-

$806 \quad 329$.

807 Damisch, L., Stoberock, B., \& Mussweiler, T. (2010). Keep your fingers crossed! how

808 superstition improves performance. Psychological Science, 21(7), 1014-1020.

809 doi:http://dx.doi.org.myaccess.library.utoronto.ca/10.1177/0956797610372631

810 Dehaene, S., Posner, M. I., \& Tucker, D. M. (1994). Localization of a neural system for error

811 detection and compensation. Psychological Science, 5(5), 303-305.

812 doi:http://dx.doi.org.myaccess.library.utoronto.ca/10.1111/j.1467-9280.1994.tb00630.x

813 Diamond, A. (2013). Executive functions. Annual Review of Pscyhology, 64, 135-168.

814 Dulaney, S., \& Fiske, A. P. (1994). Cultural rituals and obsessive-compulsive disorder: Is there a common psychological mechanism? Ethos, 22, 243-283.

816 Edwards, L. J., Muller, K. E., Wolfinger, R. D., Qaqish, B. F., \& Schabenberger, O. (2008).

817 An $R^{2}$ statistic for fixed effects in the linear mixed model. Statistics in Medicine, 27, 6137-

$818 \quad 6157$.

819 Endrass, T., Schreiber, M., \& Kathmann, N. (2012). Speeding up older adults: Age effects on 820 processing in speed and accuracy conditions. Biological Psychology, 89, 426-432.

821 Faul, F., Erdfelder, E., Lang, A., \& Buchner, A. (2007). G*Power 3: A flexible statistical power

822 analysis program for the social, behavioral, and biomedical sciences. Behavior Research

823 Methods, 39(2), 175-191. doi:http://dx.doi.org/10.3758/BF03193146 
824 Foster, D. J., Weigand, D. A., \& Baines, D. (2006). The effect of removing superstitious

825 behavior and introducing a pre-performance routine on basketball free-throw performance.

826 Journal of Applied Sport Psychology, 18(2), 167-171.

827 doi:http://dx.doi.org.myaccess.library.utoronto.ca/10.1080/10413200500471343

828 Geertz, C. (1973). The interpretation of cultures. New York, NY: Basic Books.

829 Gehring, W. J., Himle, J., \& Nisenson, L. G. (2000). Action-monitoring dysfunction in

830 obsessive-compulsive disorder. Psychological Science, 11, 1-6.

831 Good, M., Inzlicht, M., \& Larson, M. J. (2015). God will forgive: Reflecting on god's love

832 decreases neurophysiological responses to errors. Social Cognitive and Affective

$833 \quad$ Neuroscience, 10, 357-363.

834 Gratton, G., Coles, M. G., \& Donchin, E. (1983). A new method for off-line removal of ocular

835 artifact. Electroencephalography \& Clinical Neurophysiology, 55(4), 468-484.

836 doi:http://dx.doi.org.myaccess.library.utoronto.ca/10.1016/0013-4694(83)90135-9

837 Gueorguieva, R., \& Krystal, J. H. (2004). Move over ANOVA: Progress in analyzing repeated-

838 measures data and its reflection in papers. Archives of General Psychiatry, 61, 310-317.

839 Hajcak, G., \& Foti, D. (2008). Errors are aversive: Defensive motivation and the error-related

$840 \quad$ negativity. Psychological Science, 19, 103-108.

841 Hajcak, G., McDonald, N., \& Simons, R. (2003). Anxiety and error-related brain activity.

842 Biological Psychology, 64, 77-90.

843 Hajcak, G., McDonald, N., \& Simons, R. (2004). Error-related psychophysiology and negative

$844 \quad$ affect. Brain and Cognition, 56, 189-197.

845 Hajcak, G., Moser, J. S., Yeung, N., \& Simons, R. F. (2005). On the ERN and the significance of 846 errors. Psychophysiology, 42, 151-160. 
847 Herrmann, P. A., Legare, C. H., Harris, P. L., \& Whitehouse, H. (2013). Stick to the script: The 848 effect of witnessing multiple actors on children's imitation. Cognition, 129, 536-543.

849 Hirsh, J. B., Mar, R. A., \& Peterson, J. B. (2012). Psychological entropy: a framework for 850 understanding uncertainty-related anxiety. Psychological Review, 119, 304-320.

851 Hobson, N. M., Gino, F., Norton, M. I., \& Inzlicht, M. (in press). When novel rituals impact 852 intergroup bias: Evidence from economic games and neurophysiology. Psychological $853 \quad$ Science.

854 Hobson, N. M., \& Inzlicht, M. (2016). Recognizing religion’s dark side: Religious ritual 855 increases antisociality and hinders self-control. Behavioral and Brain Sciences, 39, 30-31. 856 Hobson, N. M., Saunders, B., Al-Khindi, T., \& Inzlicht, M. (2014). Emotion down-regulation 857 diminishes cognitive control: a neurophysiological investigation. Emotion, 14, 1014-1026. 858 Holroyd, C. B., \& Coles, M. G. H. (2002). The neural basis of human error processing: reinforcement learning, dopamine, and the error-related negativity. Psychological Review, 109, 679-709.

861

862

863

864 865

866 867 868

Inzlicht, M., \& Al-Khindi, T. (2012). ERN and the placebo: A misattribution approach to studying the arousal properties of the error-related negativity. Journal of Experimental Psychology: General, 141(4), 799-807. doi:http://dx.doi.org.myaccess.library.utoronto.ca/10.1037/a0027586

Inzlicht, M., Bartholow, B. D., \& Hirsh, J. B. (2015). Emotional foundations of cognitive neuroscience. Trends in Cognitive Sciences, 19, 126-132.

Inzlicht, M., \& Gutsell, J. N. (2007). Running on empty: Neural signals for self-control failure. Psychological Science, 18, 933-937. 
869 Inzlicht, M., \& Legault, L. (2014). In J. Forgas \& E. Harmon-Jones (Eds.), The Control Within:

870 Motivation and its Regulation (pp. 115-132). New York: Psychology Press.

871 Inzlicht, M., McGregor, I., Hirsh, J. B., \& Nash. K. (2009). Neural markers of religious

872 conviction. Psychological Science, 20, 385-392.

873 Inzlicht, M., \& Tullett, A. M. (2010). Reflecting on god: Religious primes can reduce

874 neurophysiological response to errors. Psychological Science, 21(8), 1184-1190.

875 Irons, W. (1996). Morality, Religion, and Human Nature. In W. Mark Richardson and Wesley

876 Wildman (Eds.), Religion and Science: History, Method, Dialogue (pp. 375-399). New

877 York: Routledge, Inc.

878 Jackson, R. C., \& Masters, R. S. W. (2006). Ritualized behavior in sport. Behavioral Brain

$879 \quad$ Sciences, 29, 621-622.

880 Jackson, F., Nelson, B. D., \& Hajcak, G. (2016). The uncertainty of errors: Intolerance of

881 uncertainty is associated with error-related brain activity. Biological Psychology, 113, 52-

$882 \quad 58$.

883 Kapitány, R., \& Nielsen, M. (2015). Adopting the ritual stance: The role of opacity and context

884 in everyday actions. Cognition, 145, 13-29.

885 Kapitány, R., \& Nielsen, M. (2016). The ritual stance and the precaution system: The role of

886 goal-demotion and opacity in ritual and everyday actions. Religion, Brain, and Behavior.

887 Advance online publication. doi: 10.1080/2153599X.2016.1141792

888 King, A. (2006). The word of command: Communication and cohesion in the military. Armed

$889 \quad$ Forces and Society, 32, 493-512.

890 Lang, M., Krátký, J., Shaver, J. H., Jerotijevic, D., \& Xygalatas, D. (2015). Effects of anxiety on 891 spontaneous ritualized behavior. Current Biology, 25, 1-6. 
892 Legare, C., \& Souza, A. (2012). Evaluating ritual efficacy: evidence from the supernatural. $893 \quad$ Cognition, 124, 1-15.

894 Legare, C. H., Wen, N. J., Herrmann, P. A., \& Whitehouse, H. (2015). Imitative flexibility and 895 the development of cultural learning. Cognition, 142, 351-361.

896 Legault, L., \& Inzlicht, M. (2013). Self-determination, self-regulation, and the brain: Autonomy 897 improves performance by enhancing neuroaffective responsiveness to self-regulation failure. $898 \quad$ Journal of Personality and Social Psychology, 105(1), 123-138.

899 doi:http://dx.doi.org.myaccess.library.utoronto.ca/10.1037/a0030426

900 Lobmeyer, D. L., \& Wasserman, E. A. (1986). Preliminaries to free throw shooting:

901 Superstitious behavior? Journal of Sport Behavior, 9(2), 70-78.

902 Luck, S. J. (2005). An introduction to the event-related potential technique. Cambridge, 903 MA: MIT Press.

904 Luck, S. J., \& Gaspelin, N. (in press). How to get statistically significant effects in any ERP 905 experiment (and why you shouldn't). Psychophysiology.

906

907

908

909

910

911

912

913

Maier, M. E., Scarpazza, C., Starita, F., Filogamo, R., \& Làdavas, E. (2016). Error monitoring is related to processing internal affective states. Cognitive, Affective, \& Behavioral Neuroscience, 16, 1-13.

Malinowski, B. (1954). Magic, science and religion and other essays. Garden City, NY: Doubleday.

Masters, R. S. W. (1992). Knowledge, knerves and know-how: The role of explicit versus implicit knowledge in the breakdown of complex motor skill under pressure. British Journal of Pychology, 83, 343-358. 
914 Masters, R. S. W., \& Maxwell, J. (2008). The theory of reinvestment. International Review of $915 \quad$ Sport and Exercise Psychology, 1, 160-183.

916 Mathalon D. H., Fedor M., Faustman W.O., Gray M., Askari N., Ford J.M. (2002). Response-

917 monitoring dysfunction in schizophrenia: an event-related brain potential study. Journal of 918 Abnormal Psychology, 111, 22-41.

919 Mathalon, D. H., Whitfield, S. L., \& Ford, J. M. (2003). Anatomy of an error: ERP and fMRI. 920 Biological Psychology, 64, 119-141.

921 McNeill, W. H. (1997). Keeping together in time: Dance and drill in human history. Cambridge, 922 MA: Harvard University Press.

923 Moser, J. S., Moran, T. P., Schroder, H. S., Donnellan, M. B., \& Yeung, N. (2013). On the 924 relationship between anxiety and error monitoring: a meta-analysis and conceptual 925 framework. Frontiers in Human Neuroscience, 15,

$926 \quad$ https://doi.org/10.3389/fnhum.2013.00466

927 Norton, M. I., \& Gino, F. (2013). Rituals alleviate grieving for loved ones, lovers, and lotteries.

928 Journal of Experimental Psychology: General, 143(1), 266-272.

929 doi:http://dx.doi.org.myaccess.library.utoronto.ca/10.1037/a0031772

930 Olvet, D. M., \& Hajcak, G. (2009). The effect of trial-to-trial feedback on the error-related 931 negativity and its relationship with anxiety. Cognitive, Affective \& Behavioral 932 Neuroscience, 9(4), 427-433. doi:http://dx.doi.org/10.3758/CABN.9.4.427

933 Olvet, D. M., \& Hajcak, G. (2009). The stability of error-related brain activity with increasing 934 trials. Psychophysiology, 46, 957-961.

935 Pailing, P. E., \& Segalowitz, S. J. (2004). The effects of uncertainty in error monitoring on 936 associated ERPs. Brain Cognition, 56, 215-233. 
937 Pietschmann, M., Simon, K., \& Endrass, T. (2008). Changes of performance monitoring with

938 learning in older and younger adults. Psychophysiology, 45, 559-568.

939 Predebon, J., \& Docker, S. B. (1992). Free-throw shooting performance as a function of preshot $940 \quad$ routines. Perceptual and Motor Skills, 75(1), 167-171.

941 doi:http://dx.doi.org.myaccess.library.utoronto.ca/10.2466/PMS.75.4.167-171

942 Proudfit, G. H., Inzlicht, M., \& Mennin, D. (2013). Anxiety and error monitoring: The 943 importance of motivation and emotion. Frontiers in Human Neuroscience, 7, 1-4.

944 Reynolds, M. (2011). A simple ritual that will make your goals “stick": Five tips for achieving 945 your goals, Psychology Today, https://www.psychologytoday.com/blog/wanderwoman/201104/simple-ritual-will-make-your-goals-stick.

947 Richard, F. D., Bond, C. F., Jr., \& Stokes-Zoota, J. (2001). "That's completely obvious...and important": Lay judgments of social psychological findings. Personality and Social Psychology Bulletin, 27(4), 497-505. doi:http://dx.doi.org/10.1177/0146167201274010

Risen, J. L. (2016). Believing what we do not believe: Acquiescence to superstitious beliefs and other powerful intuitions. Psychological Review, 123, 182-207.

Rotella, R. J., \& Cullen, B. (1995). Golf is Not a Game of Perfect. New York: Simon \& Schuster.

Rook, D. W. (1985). The ritual dimension of consumer behavior. Journal of Consumer Research, 251-264.

Rossano, M. J. (2012). The essential role of ritual in the transmission and reinforcement of social norms. Psychological Bulletin, 138(3), 529-549. doi:http://dx.doi.org.myaccess.library.utoronto.ca/10.1037/a0027038 
958 Saunders, B., Rodrigo, A. H., \& Inzlicht, M. (2016). Mindful awareness of feelings increases 959 neural performance monitoring. Cognitive Affective and Behavioral Neuroscience, 16, 90960105.

961 Scheffers, M. K., \& Coles, M. G. (2000). Performance monitoring in a confusing world: error 962 related brain activity, judgements of response accuracy, and types of errors. Journal of 963 Experimental Psychology: Human Perception and Performance, 26, 141-151.

964 Schjoedt, U., Sørensen, J., Nielbo, K. L., Xygalatas, D., Mitkidis, P., \& Bulbulia, J. (2013).

965 Cognitive resource depletion in religious interactions. Religion, Brain, \& Behavior, 3, 3996686.

967 Segalowitz, S. J., Santesso, D. L., Murphy, T. I., Homan, D., Chantziantoniou, D. K., \& Khan, S. 968 (2010). Retest reliability of medial frontal negativities during performance 969 monitoring. Psychophysiology, 47(2), 260-270. doi:http://dx.doi.org/10.1111/j.14698986.2009.00942.x

971 Sosis, R. (2000). Costly signaling and torch fishing on ifaluk atoll. Evolution and Human 972 Behavior, 21(4), 223-244. doi:http://dx.doi.org.myaccess.library.utoronto.ca/10.1016/S1090-5138(00)00030-1

974

975

976

977

978

979 980

Stroop, J. R. (1935). Studies of interference in serial verbal reactions. Journal of Experimental Psychology, 18, 643-662.

Tullett, A. M., Kay, A. C., \& Inzlicht, M. (2015). Randomness increases self-reported anxiety and neurophysiological correlates of performance monitoring. Social Cognitive Affective Neuroscience, 10, 628-635.

van Veen, V., \& Carter, C. S. (2002). The timing of action-monitoring processes in the anterior cingulate cortex. Journal of Cognitive Neuroscience, 14, 593-602. 
981 Vohs, K. D., Wang, Y., Gino, F., \& Norton, M. I. (2013). Rituals enhance consumption. $982 \quad$ Psychological Science, 24(9), 1714-1721.

983 Weinberg, A., \& Hajcak, G. (2011). Electrocortical evidence for vigilance then avoidance in 984 Generalized Anxiety Disorder: An event-related potential study. Psychophysiology, 48, $985 \quad 842-851$.

986 Weinberg, A., Riesel, A., \& Hajcak, G. (2012). Integrating multiple perspectives on error-related 987 brain activity: The ERN as a neural indicator of trait defensive reactivity. Motivation and $988 \quad$ Emotion, 26, 84-100.

989 Wen, N. J., Herrmann, P. A., \& Legare, C. H. (2016). Ritual increases children's affiliation with 990 in-group members. Evolution and Human Behavior, 37, 54-60.

991 Wiswede, D., Münte, T. F., \& Rüsseler, J. (2009). Negative affect induced by derogatory verbal 992 feedback modulates the neural signature of error detection. Social Cognitive and Affective $993 \quad$ Neuroscience, 4, 227-237.

994 Yeung, N., Botvinick, M. M., \& Cohen, J. D. (2004). The neural basis of error detection:

995 Conflict monitoring and the error-related negativity. Psychological Review, 111(4), 931996 959. doi:http://dx.doi.org.myaccess.library.utoronto.ca/10.1037/0033-295X.111.4.931

997 Zhang, Y., Risen, J. L., \& Hosey, C. (2014). Reversing one's fortune by pushing away bad luck. 998 Journal of Experimental Psychology: General, 143, 1171-1184.

999

1000

1001

1002

1003 


\section{Notes}

i Superstitions are a style of thinking that have been linked to rituals (see Risen, 2016; Zhang, Risen, \& Hosey, 2014). A ritual may involve an element of superstitious thought like when the behavior of knocking on wood (ritual) is coupled with the belief that doing so pushes away bad luck (superstition). Of course, since superstitions are thought based, a person may have a superstition but without the overt ritual behavior or action. The key piece being that ritual is considered the coming together of symbolic thought with outward directed action (Geertz, 1973). ii Upon visual inspection of the ERP graphs, it appears there might be an effect of the Pe -- a later, slower moving error-related waveform that is thought to be tied to the conscious awareness of error commission. To explore this, we conducted similar analyses looking at the Pe as defined as the average mean amplitude between 200 and $400 \mathrm{~ms}$ following responses on error trials at the posterior electrode site, Pz. The model revealed a significant main effect of trial type, $b=9.50$, $t(46)=4.89, S E=1.94, p<.00001,95 \% \mathrm{CIs}=[5.59,13.40]$, indicating that the Pe was larger for error responses $(M=8.29 \mu \mathrm{V}, S E=1.35)$ compared to correct responses $(M=-2.68 \mu \mathrm{V}, S E=$ 1.02). There were no other significant main effects or interactions (all $p s>.15$ ). 